\title{
Quantitative Analysis of Criteria in University Building Maintenance in Malaysia
}

Olanrewaju Ashola AbdulLateef, (Department of Civil Engineering, Universiti Teknologi Petronas)

\begin{abstract}
University buildings are a significant part of university assets and considerable resources are committed to their design, construction and maintenance. The purpose of maintenance management is to optimize productivity and user satisfaction with minimum resources. This paper aims to identify, quantify, rank and discuss the criteria that influence maintenance costs, maintenance backlogs, user productivity and user satisfaction in relation to Malaysian university buildings. Following a review of the related literature, a questionnaire survey identifying thirty one factors which impact effective building maintenance management was issued to 50 university maintenance organizations. Participants were required to evaluate the degree to which each of the identified criteria influences effective building maintenance management. The survey achieved a $66 \%$ response rate. Survey results conclusively identified that quality of original components and materials, budget constraints and the age of the building/s are the most influential criteria. Problems associated with in-house workforce, shortage of materials and components were identified as the least influential criteria. This paper also establishes that maintenance management is a strategic function in university administration.
\end{abstract}

Keywords: University buildings, Maintenance management, Service delivery, Malaysia

\section{Introduction}

This paper reports part of an ongoing research study. The main research seeks to develop a systemic university building maintenance management model. The aim of this present paper is to report a study on the analysis of the criteria that influence the management of the university buildings maintenance in Malaysia. In order to achieve the set aim, the study identifies, quantifies, ranks and discusses the criteria that affect maintenance costs, user satisfaction, organizational productivity and total service delivery. The study combines a literature review with a questionnaire survey and analysis to achieve its aim. Data obtained was analyzed using SPSS to produce statistics.

The major conclusion drawn from the survey was that although there are many different criteria that influence maintenance management, some exert a greater influence than others. In order to model systemic maintenance management for university buildings the inclusion of the identified criteria is critical. Furthermore, the paper argues that building maintenance is a strategic issue for an academic institution. The failure of universities to accept maintenance as a core service is a serious flaw on the part of a sector that prides itself on being a vehicle for change and advancement. The remainder of the paper is structured as follows; An overview of the relevant literature concerning university building maintenance; discussion of the research and data analysis methodology adopted; presentation and discussion of data analysis; major findings and conclusions. 


\section{Literature Review and Background}

Education is a very significant and integral part of the Malaysian Strategic Thrust. The economy of Malaysia has, since independence, been planned based on five-year strategic plans. For each of the plans, the education sector has featured prominently in terms of value and policy implementation. Malaysia is now an educational hub and a destination for students from many countries, particularly Africa, Asia Pacific, Europe, America and the Middle East. Malaysia's quest to transform itself into a high income, knowledge based economy is a primary government focus. Under the current Malaysian Plan or 10 PM (2010-2015) universities are expected to contribute significantly to the Malaysian high-income economy status. This will require the universities to produce graduates who can meaningfully contribute regionally and globally towards economic and technological advancements and also for the universities to be able to commercialize any knowledge advancements. In order for the university sector to achieve these outcomes, university infrastructure must adequately meet the physical needs of world-class teaching, learning and research environments.

The business of a university is to transmit and disseminate knowledge and culture, teach and conduct scientific research. University assets comprise finance, technology, humans, equipment and plant as well as the constructed facilities (i.e. buildings). The human resource is considered the most significant resource of the university organization because university education is labour intensive (Miller 2007). Nonetheless, apart from human resources, buildings are the second most significant asset of a university institution. University buildings are procured to create a suitable, conducive environment to support, stimulate and encourage learning, teaching, innovation and research.

Furthermore, a number of studies (Housley 1997, Price, Matzdorf, Smith \& Agahi 2003, Green \& Turrell 2005, Lavy \& Bilbo 2009) have affirmed positive correlations between the performance of educational buildings and the quality of education. Constructing new buildings helps in providing better quality education. It is equally important to maintain performance standards of existing buildings for facilitating the transfer and development of knowledge and other academic related activities.

Buildings are critical factors of production in achieving desirable outcomes for university institutions. Any inadequacy in building facilities represents a loss in value to the university institution, its users and other stakeholders. On the one hand, it is not possible to replace or rebuild all of an organization's buildings at one time. As an illustration, the replacement costs of the sixties buildings in English universities alone are estimated to be $£ 11$ billion (Rawlinson \& Brett 2009). On the other hand, buildings cannot remain new throughout their entire life. In fact, before a building is completed, maintenance problems start to creep in. Therefore, the need for maintenance will only intensify. Building maintenance constantly affects everyone's life because people's comfort and productivity depend on the performance of the buildings they live, learn, conduct research and work in (e.g. homes, offices, schools, universities and markets). Universities need functional buildings to operate. Even virtual universities require some minimum amount of building to carry out their business.

"Maintenance" in this paper, is defined as the required processes and services carried out to preserve, repair, protect and care for a building's fabric and engineering services after completion, repair, refurbishment or replacement to current standards to enable it to serve its intended functions throughout its entire life span without drastically upsetting its basic features and use (Olanrewaju 2010). From this definition, maintenance is not necessarily about the building per se but rather about the occupants of the buildings. Therefore, "user care" is / should be the focus of maintenance. This is illustrated thus. Buildings are procured for the sake of the

Olanrewaju, A A (2010) 'Quantitative analysis of criteria in university building maintenance in Malaysia', Australasian Journal of Construction Economics and Building, 10 (3) 51-61 
services (i.e. comfort, protection, accommodation, security and esteem) they offer to their users. It is the correct functioning of the building that the users desire, not the physical condition of the building. To the extent that the building is capable of allowing the users to perform their functions, the building is a source of value creation to the functional service of accommodating, learning, teaching and doing research-with specific reference to the university buildings.

In Malaysia, there is no conclusive statistical data on the size of maintenance of university buildings. However, based on the data obtained from the Ministry of Higher Education, maintenance expenditure had expanded by nearly 85\% from 2004 to 2008. For instance, expenditure on maintenance was nearly 340 million in 2004 while it increased to more than 600 million in 2008 even though the figure for 2008 was at July 2008 . Therefore, the size and scope of university building maintenance is huge and at the same time is on the increase. However, when comparing these amounts with the total expenditure on education, it can be seen that the government is investing roughly $1 \%$ on university building maintenance. This is, however, inadequate, to cater for maintenance backlogs. However, the $1 \%$ may not be the issue per se; the main issue is with the total allocation to higher education as a sector. There are already signs of constraints in financing higher education. For example, public universities are been encouraged by the government to enter into public-private initiatives to finance some of their projects. Primary factors that determine maintenance costs include the expected life span of the buildings, the quality of original materials and workmanship as well as the quality of maintenance invested in these buildings.

It is most unlikely that a complete solution can be identified without an increase in funding allocation to the maintenance sector. Nevertheless it is possible to improve building performance through a better management philosophy. Building maintenance is an economic issue and needs to be considered as an investment in maintaining building performance rather than as a reaction to inadequate building performance. Total maintenance management requires a multi-disciplinary approach: from the engineering, technological, commercial, economic and social perspectives. Strictly speaking, maintenance is business. The maintenance department should be seen as a business unit.

The most important segment in the total management of university buildings is the analysis of criteria that influence total maintenance management. This paper is based on the hypothesis that information on and knowledge of the criteria that influence maintenance of university buildings are positively correlated to user satisfaction, maintenance costs and organizational productivity. The lack of this knowledge and information would imply that the scarce resources will not be strategically and positively managed. Poor maintenance management systems will lead to unnecessary increases in maintenance costs, poor user satisfaction and low productivity.

\section{Research Design and Method of Data Analysis}

A questionnaire survey approach was used to collect primary data. The questionnaires were administered on 50 universities in Malaysia. The list was drawn from a database prepared by the Ministry of Higher Education. Though it was not the intention of the research to carry out a census, all the universities were involved in order to boost the response rate. The questionnaire was designed with consideration of those previously conducted by Springer and Waller (1996), Buys and Nkado (2006), Amaratunga and Baldry (2000), Shen, Lo and Wang (1998), El-Haram and Horner (2002) and Chanter and Swallow (2007) and a series of discussions with persons engaged in university building management. 
Thirty-one criteria were identified and addressed to the respondents. The data collection and collation commenced in July 2009 and lasted through to October 2009. A questionnaire with a cover letter was posted to individual university maintenance organizations ("maintenance managers"). The respondents were identified by their names and positions. It was found that addressing the letter to an individual respondent would encourage high participation. It was considered that the maintenance managers in the university maintenance organizations are appropriate to respond to the questionnaire because they are the people who establish the goals and objectives of the organizations. A self-addressed, prepaid envelope was provided to facilitate return.

The respondents were asked to rank the 31 criteria in order of the influence they have on maintenance management. The criteria were previously identified as major sources of building maintenance related problems for the university sector. The following five-point ranking scale was used: 1 - not at all influential, 2 - not influential, 3- influential, 4- very influential, and 5extremely influential.

The degree of influence of each of the criteria is determined by the mean and mode scores tests of each of the criteria. Standard Deviation is also calculated to determine the level of spread of each of the individual values from the mean score. From the individual mean score tests, the average mean score was determined. Missing data (i.e. where the respondent refused to tick where applicable or where there is a multiple entry) could have a negative impact on the outcome of the findings. Such an effect could be improved during data analysis by replacing the missing data with either the mode or mean of the data. Nevertheless, in this paper the missing data is not treated as such; instead, the authors prefer to leave the data raw, as it were, so that the outcomes will not in any way be influenced by the authors.

\section{Results and Discussion}

\section{Demographic profile of the respondents}

This section presents the findings and discussions of the questionnaire survey. Thirty-three questionnaires were returned and analyzed for this study. This is a response rate of $66 \%$. This is considered very satisfactory for a postal survey. According to authors like Sekeran and Bougie (2010), $30 \%$ is the common response rate for postal surveys. However, this high response rate was possible because of the long survey duration and the numerous reminders sent to the respondents. Analysis of the outcome of the survey shows that most of the respondents possessed sound academic qualifications. For instance, the survey revealed that about $50 \%$ of the respondents possessed a Bachelor's degree and $21.9 \%$ had obtained MSc degrees. The survey responses were differentiated into two categories depending on whether they are from private or public universities. From the 50 surveyed universities, 33 responded, which involved 17 (51.5\%) private and 16 (48.5\%) public universities respectively.

The survey revealed that most of the respondents hold strategic positions. Nearly $32 \%$ of the respondents were actually maintenance managers while about $19 \%$ were facilities managers. A substantial proportion of the "others" are directors of development and/or maintenance "executives". Maintenance executive is synonymous with maintenance manager. Whatever the name given to the roles of the maintenance manager (maintenance executive, property manager or general manager) or the maintenance organizations (asset manager, facility manager or development division) the common intent is the same. The main issue is that one individual takes the overall control and responsibility for managing the activities of the various personnel. Table 1 contains the annual maintenance budgets and respondents' industrial experience. The Table also contains the respondents' industrial working experience. Thus it

Olanrewaju, A A (2010) 'Quantitative analysis of criteria in university building maintenance in Malaysia', Australasian Journal of Construction Economics and Building, 10 (3) 51-61 
could be inferred that the majority of respondents have sufficient knowledge to complete the questionnaires.

\begin{tabular}{|l|c|c|l|c|c|}
\hline \multicolumn{3}{|c|}{ Annual maintenance budget (RM) } & \multicolumn{3}{c|}{ Respondent's working experience } \\
\hline Budget (million) & Frequency & Percentage & Experience & Frequency & Percentage \\
\hline Less than 10 & 16 & 51.6 & $\begin{array}{l}\text { Less than five } \\
\text { years }\end{array}$ & 15 & 46.9 \\
\hline 10 to 20 & 12 & 38.7 & $\begin{array}{l}\text { Five years to ten } \\
\text { years year to }\end{array}$ & 7 & 21.9 \\
\hline 20 to 30 & 1 & 3.2 & $\begin{array}{l}\text { Ten years } \\
\text { fifteen years }\end{array}$ & 5 & 15.6 \\
\hline 30 to 40 & 2 & 6.5 & $\begin{array}{l}\text { Fifteen years and } \\
\text { above }\end{array}$ & 5 & 15.6 \\
\hline Total & $\mathbf{3 1}$ & $\mathbf{1 0 0 . 0}$ & Total & 32 & 100.0 \\
\hline
\end{tabular}

Table 1 Annual maintenance budgets and respondents' working experience Note: 1 USD = RM 3.15

Table 2 contains the built-up areas for the surveyed universities. The Table also contains the average age of buildings in the university campuses. From this it could be inferred that most of the university buildings are not that old, although a considerable amount of money is invested in their maintenance. Nevertheless, there are considerable complaints about maintenance practices.

\begin{tabular}{|l|c|c|c|c|c|}
\hline \multicolumn{3}{|c|}{ Size of the university built-up area (m2) } & \multicolumn{3}{c|}{ Age of buildings (yrs) } \\
\hline & Frequency & Percentage & Age & Frequency & Percentage \\
\hline $\begin{array}{l}\text { Less than } \\
40,000\end{array}$ & 7 & 21.9 & Less than 10 & 10 & 32.3 \\
\hline $\begin{array}{l}40,000 \text { to } \\
50,000\end{array}$ & 5 & 15.6 & 10 to 20 & 13 & 41.9 \\
\hline $\begin{array}{l}60,000 \text { to } \\
70,000\end{array}$ & 2 & 6.2 & 20 to 30 & 5 & 16.1 \\
\hline $\begin{array}{l}70,000 \text { to } \\
80,000\end{array}$ & 1 & 3.1 & 30 to 40 & 1 & 3.2 \\
\hline $\begin{array}{l}90,000 \text { to } \\
100,000\end{array}$ & 3 & 9.4 & 40 to 50 & 2 & 6.5 \\
\hline $\begin{array}{l}100,000 \text { and } \\
\text { above }\end{array}$ & 14 & 43.8 & Total & 31 & 100.0 \\
\hline Total & $\mathbf{3 2}$ & $\mathbf{1 0 0 . 0}$ & & & \\
\hline
\end{tabular}

Table 2 University built-up area and average age of buildings

\section{Criteria that influence maintenance management}

Reliability test results indicate that the Cronbach alpha for all the criteria is very satisfactory (Cronbach's Alpha: 0.923). Thus, the internal consistency reliability of the criteria used is considered excellent. The validity score also ranges from 0.571 to 0.905 . This also signifies the high validity of the result. Table 3 contains the statistics for criteria. From the analysis, the average means score test for all the criteria was found to be 3.183 . 


\begin{tabular}{|c|c|c|c|c|c|c|c|c|}
\hline \multirow{2}{*}{ Criteria } & \multicolumn{5}{|c|}{ Level of influential (Mode values) } & \multirow{2}{*}{ Mean } & \multirow{2}{*}{ SD } & \multirow{2}{*}{ Ranking } \\
\hline & 1 & 2 & 3 & 4 & 5 & & & \\
\hline Use of the building & $6.3 \%$ & $9.4 \%$ & $43.8 \%$ & $31.3 \%$ & $9.4 \%$ & 3.2813 & 0.9914 & 16 \\
\hline Budget constraints & $0.0 \%$ & $12.1 \%$ & $21.2 \%$ & $39.4 \%$ & $27.3 \%$ & 3.8182 & 0.9828 & 2 \\
\hline $\begin{array}{l}\text { Information on } \\
\text { performance satisfaction }\end{array}$ & $0.0 \%$ & $25 \%$ & $50 \%$ & $21.9 \%$ & $3.1 \%$ & 3.0313 & 0.7822 & 29 \\
\hline Staff training / development & $0.0 \%$ & $6.1 \%$ & $51.5 \%$ & $30.3 \%$ & $12.1 \%$ & 3.4848 & 0.7954 & 8 \\
\hline $\begin{array}{l}\text { Quality of components and } \\
\text { materials }\end{array}$ & $0.0 \%$ & $3.1 \%$ & $37.5 \%$ & $31.3 \%$ & $28.1 \%$ & 3.8438 & 0.8839 & 1 \\
\hline Maintenance programme & $9.1 \%$ & $24.2 \%$ & $27.3 \%$ & $30.3 \%$ & $9.1 \%$ & 3.0606 & 1.1440 & 24 \\
\hline Budgeting control & $9.1 \%$ & $21.2 \%$ & $24.2 \%$ & $39.4 \%$ & $6.1 \%$ & 3.1212 & 1.1112 & 20 \\
\hline $\begin{array}{l}\text { Maintenance performance } \\
\text { indicator }\end{array}$ & $6.1 \%$ & $18.2 \%$ & $39.4 \%$ & $33.3 \%$ & $3.0 \%$ & 3.0909 & 0.9475 & 22 \\
\hline Building automation system & $0.0 \%$ & $34.4 \%$ & $34.4 \%$ & $25.0 \%$ & $6.3 \%$ & 3.0313 & 0.9327 & 27 \\
\hline Lack of skilled personnel & $3.0 \%$ & $12.1 \%$ & $30.3 \%$ & $42.4 \%$ & $12.1 \%$ & 3.4848 & 0.9722 & 7 \\
\hline Age of building & $0.0 \%$ & $12.1 \%$ & $27.3 \%$ & $48.5 \%$ & $12.1 \%$ & 3.6061 & 0.8638 & 3 \\
\hline $\begin{array}{l}\text { Problems associated with in- } \\
\text { house workforce }\end{array}$ & $3.0 \%$ & $18.2 \%$ & $54.5 \%$ & $24.2 \%$ & $0.0 \%)$ & 3.0000 & 0.7500 & 30 \\
\hline $\begin{array}{l}\text { Shortage of materials and } \\
\text { components }\end{array}$ & $9.1 \%$ & $27.3 \%$ & $42.4 \%$ & $12.1 \%$ & $9.1 \%$ & 2.8485 & 1.0642 & 31 \\
\hline $\begin{array}{l}\text { Problems associated with } \\
\text { outsourcing }\end{array}$ & $0.0 \%$ & $27.3 \%$ & $45.5 \%$ & $21.2 \%$ & $6.1 \%$ & 3.0606 & 0.8638 & 25 \\
\hline $\begin{array}{l}\text { Involving maintenance expert } \\
\text { during design stage }\end{array}$ & $6.1 \%$ & $12.1 \%$ & $27.3 \%$ & $27.3 \%$ & $27.3 \%$ & 3.5758 & 1.1998 & 4 \\
\hline Worker motivation & $0.0 \%$ & $16.1 \%$ & $41.9 \%$ & $32.3 \%$ & $9.7 \%$ & 3.3548 & 0.8774 & 14 \\
\hline $\begin{array}{l}\text { Trust and confidence among } \\
\text { staff }\end{array}$ & $0.0 \%$ & $29.0 \%$ & $35.5 \%$ & $32.3 \%$ & $3.2 \%$ & 3.0968 & 0.8701 & 21 \\
\hline $\begin{array}{l}\text { Application of maintenance } \\
\text { management software }\end{array}$ & $9.7 \%$ & $22.6 \%$ & $32.3 \%$ & $25.8 \%$ & $9.7 \%$ & 3.0323 & 1.1397 & 26 \\
\hline $\begin{array}{l}\text { Lack of effective } \\
\text { communication }\end{array}$ & $0.0 \%$ & $16.1 \%$ & $45.2 \%$ & $25.8 \%$ & $12.9 \%$ & 3.3548 & 0.9146 & 13 \\
\hline Lack of maintenance manuals & $0.0 \%$ & $15.6 \%$ & $46.9 \%$ & $34.4 \%$ & $3.1 \%$ & 3.2500 & 0.7620 & 18 \\
\hline Effective organization structure & $0.0 \%$ & $12.5 \%$ & $37.5 \%$ & $37.5 \%$ & $12.5 \%$ & 3.5000 & 0.8799 & 6 \\
\hline $\begin{array}{l}\text { Lack of maintenance } \\
\text { standards }\end{array}$ & $0.0 \%$ & $21.9 \%$ & $40.6 \%$ & $28.1 \%$ & $9.4 \%$ & 3.2500 & 0.9158 & 17 \\
\hline Top management support & $6.3 \%$ & $3.1 \%$ & $37.5 \%$ & $37.5 \%$ & $15.6 \%$ & 3.5313 & 1.0155 & 5 \\
\hline $\begin{array}{l}\text { Competency of maintenance } \\
\text { managers }\end{array}$ & $9.4 \%$ & $3.1 \%$ & $34.4 \%$ & $37.5 \%$ & $15.6 \%$ & 3.4688 & 1.1067 & 9 \\
\hline Complexity of design & $6.5 \%$ & $16.1 \%$ & $45.2 \%$ & $29.0 \%$ & $3.2 \%$ & 3.0645 & 0.9286 & 23 \\
\hline $\begin{array}{l}\text { Availability of building service } \\
\text { register }\end{array}$ & $3.1 \%$ & $21.9 \%$ & $43.8 \%$ & $18.8 \%$ & $12.5 \%$ & 3.1563 & 1.0195 & 19 \\
\hline Clear maintenance objectives & $9.4 \%$ & $15.6 \%$ & $46.9 \%$ & $18.8 \%$ & $9.4 \%$ & 3.0313 & 1.0621 & 28 \\
\hline $\begin{array}{l}\text { Information on existing } \\
\text { building performance }\end{array}$ & $0.0 \%$ & $15.6 \%$ & $43.8 \%$ & $34.4 \%$ & $6.3 \%$ & 3.3125 & 0.8206 & 15 \\
\hline User expectations & $0.0 \%$ & $16.1 \%$ & $35.5 \%$ & $41.9 \%$ & $6.5 \%$ & 3.3871 & 0.8437 & 10 \\
\hline Maintenance response time & $0.0 \%$ & $12.5 \%$ & $46.9 \%$ & $31.3 \%$ & $9.4 \%$ & 3.3750 & 0.8328 & 12 \\
\hline Complaint reporting system & $6.3 \%$ & $6.3 \%$ & $46.9 \%$ & $25.0 \%$ & $15.6 \%$ & 3.3750 & 1.0395 & 11 \\
\hline Total Average Score & 0.68 & 17.64 & 25.55 & 33.60 & 22.54 & 3.1834 & 0.9460 & IV \\
\hline
\end{tabular}

Table 3 Summary of distribution of frequency and mean of the criteria

Note: $\mathrm{Vl}=$ Very Influential, SD = Standard Deviation

Olanrewaju, A A (2010) 'Quantitative analysis of criteria in university building maintenance in Malaysia', Australasian Journal of Construction Economics and Building, 10 (3) 51-61 
A total of eighteen criteria have individual mean score tests higher than the average mean test (the shaded criteria in Table 3). This indicates that the eighteen criteria were either very influential or extremely influential in total building maintenance management. Only a negligible (less than 1\%) part of the respondents considered the criteria not influential at all, while nearly $18 \%$ indicated that the criteria were not very influential. The majority of the universities $(33.6 \%)$ considered the criteria very influential and many (26\%) of them regarded the criteria as influential. A sizeable percentage (23\%) of the respondents considered the criteria to be extremely influential.

The quality of components and materials was found to be the most influential criterion, followed by budget constraints and then the age of the building. The three least influential criteria in the order of least influential were storage of materials and components, in-house workforce and information of user performance satisfaction. It is only natural that the quality of materials and components used for maintenance (and design) is given due consideration. It is not surprising that about $95 \%$ of the respondents rated the criterion as influential, very influential and extremely influential. It is natural that the use of defective or sub-standard materials will lead to maintenance problems, if not at the commissioning stage then certainly later on when the facility is in operation. Good quality materials can also fail to make the grade if used for the wrong purpose or in an unsuitable environment.

It is also not unexpected that maintenance organizations rated budget constraints highly. This finding is not surprising. In fact, it only confirmed our undisclosed hypothesis that funding allocation for maintenance is inadequate. Malaysia is already witnessing financial constraints in financing education. The government is already partnering with the private sector so that it can maintain control of the public universities. A private financial initiative contract has just been signed for the construction of an additional six campuses of Universiti Teknologi Mara. The transaction is expected to save the government RM 500 million (Nordin 2010). The reality is that it is not possible for, say, the government to provide all the funds sufficient to cater for maintenance backlogs to the publicly owned universities.

Further, it is interesting but surprising to find that the age factor was ranked as influential. The survey revealed that most $(48.5 \%)$ of the respondents concluded that deterioration due to age can significantly influence maintenance management. Nearly $27 \%$ of the respondents considered age to be influential. Some $12.1 \%$ of the respondents believed the criterion to be extremely influential. The same percentage of the respondents considered it as not very influential, however. Nevertheless, older buildings constructed of quality materials and components and using well tried and tested techniques (and which in all probability have been updated and improved) may not be subject to heavy maintenance works or expenditure. Maintenance in terms of usage hinges on and is very much related to the culture of the occupants.

The findings also revealed that the importance of maintainers' involvement is critical. This suggests that the maintenance organizations have a lot to offer to the design teams in terms of new development. This is important because design and maintenance are not always considered together. This creates a situation whereby the left hand does not know what the right hand is doing. However, maintenance is often given tactical consideration. The maintenance department is not always contacted on issues that relate to new development. While most universities consider new development a top management issue, maintenance is not given the same attention. Top management only gets involved when things go wrong. For the maintenance organization to actively support the achievement of the university's core business objectives there is a need for top officers in the university administration to support the 
maintenance organization. Maintenance issues should be discussed in the university boardroom rather than at the technical desk. Issues receive proper attention when brought to the attention of the "big boss". The Vice Chancellors, Rectors, Directors, as the case may be, should have direct access to maintenance personnel. In fact, the maintenance managers should be active members of the university governing council. The VC or Rector should be the head of the maintenance organization. In this way, maintenance issues will receive systemic attention.

This will define and clarify the lines of communication. Ninety percent of the respondents regarded organizational structure as influential, very influential and extremely influential. For effectiveness, the structure of the maintenance organization is very important. Close to $90 \%$ also believed that communication is influential, very influential and extremely influential. The lack of effective communication could lead to problems, reworks, wastes of time and contribute to poor service delivery. If the organizational structure is not well defined and effective communication is lacking, it will affect the scope and quality of maintenance and at the same time, maintenance objectives will be ambiguously defined. Under these conditions, there is no way that the user expectations and perceptions can be met or achieved.

However, while only $7 \%$ of the university organizations believed that meeting user expectations was extremely influential, a sizeable proportion (16\%) believed it is not influential. This is, indeed, unexpected. User expectations should constitute the foundation of maintenance service delivery. Customer intimacy demands that companies must have sufficient and adequate knowledge of their customers' needs and wants. The service provider must look far beyond the immediate objectives of the products or services to the users. The providers must provide a service that has wider ends than the customers realized was possible (Bartholomew 2008)

However, a likely interpretation as to why maintenance organizations do not consider that meeting users' expectations is critical could be that the respondents did not quite understand what this implied or that they believed there is no way user expectations can be meet. Alternatively, it could mean that the respondents were much more concerned about the building than the users. However, while the first justification is very unlikely, the second and the third justifications are the most likely reasons. However, it is very unfortunate that the service providers believed the users' expectations cannot be attained. This could be so where maintenance systems are not systemic and when maintenance is considered as an operational issue, only as opposed to a strategic issue. It is argued that this is the only plausible interpretation. Fifty percent of the respondents regarded having information on user performance satisfaction as influential while (25\%) considered that it is not very influential. Logically, it is only by means of a user satisfaction survey that the needs and wants of the users can be revealed. It is, therefore, most unfortunate that maintenance organizations have not appreciated the usefulness of this instrument in driving value added initiatives.

It is interesting to find that many of the respondents failed to understand that having information on building performance is influential. In fact, $25 \%$ of them also failed to appreciate the importance of a building register. Information on the building performance and previous maintenance records should be well documented in a safe register. Where this is not the case, a lot of time and effort will be wasted locating the necessary information when needed. Many of the respondents also failed to see any reason why the competencies of maintenance managers or executives are influential. However, it was good that many of them considered skilled personnel as influential and very influential at the same time as more than $90 \%$ of them saw staff training and development as influential and very influential. Labour is very important in maintenance operations. In fact, about $70 \%$ of maintenance cost is attributable to labour cost. The maintenance personnel must display a high level of competency and be able to work

Olanrewaju, A A (2010) 'Quantitative analysis of criteria in university building maintenance in Malaysia', Australasian Journal of Construction Economics and Building, 10 (3) 51-61 
cooperatively. It would not be difficult to postulate that even with high quality materials and components, the facility would eventually fail if the workers that put the objects together were not good at their jobs. Poor workmanship could be the result of lack of know-how, training and skill, or just plain negligence.

Problems associated with out-sourcing and in-sourcing were also considered influential. More than $70 \%$ of the respondents considered both criteria influential, very influential or extremely influential. Though the responses do not indicate both to be very influential and extremely influential, they are recurrent factors in maintenance issues. Often organizations like the university consider building maintenance as a non-core activity. As such, they prefer to outsource much of their services to external contractors. However, building maintenance is very critical to the survival of university organizations. Students and faculty members spend most, if not all, of their productive time in or around the classrooms, laboratories, theatres and/or tutorial rooms.

Universities should also invest in training their maintenance staff as they do for their academic staff. Substantial commitment is required for continuing professional development for the building maintenance operatives. Maintenance staff must be motivated. After all, enormous resources are committed to procure their buildings. In fact, it is a failing on the part of the university management to consider the management of their buildings as a non-core activity. Maintenance is a core activity of the university organizations, since without it the university would not survive. External maintenance organizations could hold their clients to ransom. It also leaves the in-house maintenance organization staff less competent and inactive due to redundancy. It would be more profitable if the university could use in-house operatives for most of their maintenance services.

Furthermore, another issue in outsourcing is trust and confidence. The outsourcing operatives do not see themselves as part of the mainstream staff leading to the perpetration of dubious behaviour. Analysis of reports of theft cases in a university revealed that more than $60 \%$ of the theft cases were actually carried out by operatives of 'the outsourcing' organizations. These operatives came in during their off-duty time or in the evening to commit crimes such as stealing student laptops and other valuables. This is easy since the operatives had carried out repairs to locks, doors and cupboards. They often retain the spare key when they are supposed to return it immediately to the hostel administration. It is unfortunate, however, that about $30 \%$ of the respondents failed to consider trust and confidence among staff as influential. In fact, only $3 \%$ said it was extremely important. But trust and confidence are not the only issues that are related with the outsourcing arrangement. The in-house maintenance staff should also have confidence and trust in one another. Otherwise, service delivery could be undermined.

Furthermore, empirical evidence has led to the conclusion that outsourcing could, in actual fact, be more expensive in the long run (Springer \& Waller 1996). However, times have changed. It is high time that university organizations accepted and took care of their buildings (vis-à-vis the maintenance practices) efficiently. It is no longer acceptable for a university to invest only on improving methods of teaching and learning without improving the performance of the building assets. Outsourcing maintenance always reduces maintenance procurement to a lump sum. However, the risk and uncertainty involved with maintenance services dictate that the traditional lump sum is undoubtedly unsuitable for maintenance works.

As anticipated, respondents outlined the use of buildings as very influential. The attitude of users to a building affects maintenance costs. All built assets, irrespective of the material, components or construction methods used will, as a result of use and over time, encounter

Olanrewaju, A A (2010) 'Quantitative analysis of criteria in university building maintenance in Malaysia', Australasian Journal of Construction Economics and Building, 10 (3) 51-61 
structural deterioration and systemic decline. Building users should be provided with the proper information in the form of manuals or guidebooks, not unlike those provided to someone who purchases a washing machine or toaster. Furthermore, users can be educated and maintenance manuals would also assist greatly. Whilst a number of the respondents did not think a maintenance manual has very much influence on building management, $80 \%$ of them thought otherwise.

Other aspects that a university maintenance organization must look into are the way maintenance complaints are lodged and the response time to complaints by the maintenance organization. Users prefer one point of communication and do not want complications. They want someone to talk to if a problem arises. Situations where unnecessary time is wasted in an attempt to contact the maintenance organization can only further frustrate users. They want to be able to report their complaint conveniently. The contact addresses (phone numbers) of those concerned with specific items/aspects of maintenance should be made available to the building's users. It will further facilitate easy reporting and communication if a toll-free phone can be provided so that users will not need to pay for the complaints they have made. This will go a long way to increasing the satisfaction of the users with the service delivery.

\section{Conclusions}

This paper presents the outcome of a questionnaire survey on the maintenance of university buildings. A list of criteria, which had been gathered from the literature and discussions with experts, was addressed to university maintenance organizations to evaluate their agreement on the influence the criteria have on building maintenance. Using the mean descriptive statistics technique, 18 criteria are found to be very influential or extremely influential and should be considered in maintenance decision making to enhance service delivery. The study criteria show that the criteria that influence the maintenance management of buildings cuts across technology, management, behavioral and cultural considerations and engineering. Maintenance, as a concept, is technical in nature; this is perhaps the major reason why most practitioners and authors have considered maintenance management as a hard science or purely an engineering issue. This is also where the concept of condition-based maintenance originates. However, the essence of maintenance is not about the building itself but about the users. Accordingly user satisfaction information is an essential requirement in maintenance management. The current maintenance systems regard the physical condition of the building as the main reason for maintenance demand. This paper concludes that university building maintenance is a core service of the university organization. There is a need for change in university administrators' mindsets towards buildings and maintenance.

\section{Acknowledgments}

The authors gratefully acknowledge the assistance of the respondents who provided their time and other resources to complete the questionnaires for this study. We also thank the anonymous commentators who offered useful suggestions in order to improve the paper.

\section{References}

Amaratunga, D. and Baldry, D. (2000) 'Assessment of facilities management performance in higher education properties', Facilities, 18 (7/8), 293-301

Bartholomew (2008) Building on knowledge: developing expertise, creativity and intellectual capital in the construction professional. UK: Blackwell Publishing Limited

Buys, F. and Nkado, R. (2006) A benchmark model for maintenance management systems in South African tertiary education institutions, Proceedings of the Annual Research Conference of

Olanrewaju, A A (2010) 'Quantitative analysis of criteria in university building maintenance in Malaysia', Australasian Journal of Construction Economics and Building, 10 (3) 51-61 
the Royal Institution of Chartered Surveyors (COBRA 2006), Edited by Elaine Silver, University College London 7th and 8th September 2006

El-Haram, M, A and Horner, M. W. (2002) 'Factors affecting housing maintenance cost', Journal of Quality in Maintenance Engineering, 8 (2), 115-123

Green, D. and Turrell, P. (2005) 'Schools buildings investment and impact on pupil performance', Facilities, 23 (5/6), 253-261

Housley, J. (1997) 'Managing the estate in higher education establishments', Facilities, 15 (3/4), 72-83

Lavy, S. and Bilbo, D. L. (2009) 'Facilities maintenance management in large public schools, Texas', Facilities, 27 (1/2), 5-20

Miller, B. A. (2007) Assessing organizational performance in higher education, USA: John Wiley and Sons, Inc

Nordin, M. K. (2010) Private-finance initiative can save government RM 500 million. The Star, 5 May 2010. N4

Olanrewaju, A. A. (2010). 'Maintenance Management of University Buildings', Article accepted for publication in Journal of Building Appraisal.

Price, I. F., Matzdorf, F., Smith, L. and Agahi, H. (2003) 'The impact of facilities on the student choice of university', Facilities, 21 (10), 212-222

Rawlinson, S. and Brett, L. (2009) Cost model universities, Building Magazine, Available at http://www.building.co.uk/data/cost-model-universities/3143057.article, Accessed on 15 June 2010

Sekeran, U. and Bougie, R. (2010) Research methods for business: a skill building approach, Fifth Edition, UK: John Wiley and Sons, Limited

Shen, Q.P., Lo, K.K. and Wang, Q. (1998) 'Priority setting in maintenance management of public buildings - a modified multi-attribute approach using analytic hierarchy Process', Construction Management and Economics, 16 (6), 693-702

Springer, T. M. and Waller, N. G. (1996) 'Maintenance of residential rental property: an empirical analysis', The Journal of Real Estate Research Volume, 12 (1), 89-99 